International Journal of Instruction e-ISSN: 1308-1470 • www.e-iji.net

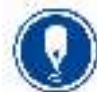

January $2021 \bullet$ Vol.14, No.1

p-ISSN: 1694-609X

pp. 661-672

Article submission code:

20190802032433

Received: 02/08/2019

Revision: 20/07/2020
Accepted: 11/08/2020

OnlineFirst:10/11/2020

\title{
Career Development: The Role of Career Counsellor towards Job Counselling
}

\section{Asrowi}

Universitas Sebelas Maret, Indonesia, asrowi@staff.uns.ac.id

\section{Muhammad Hanif D}

Universitas Pendidikan Indonesia, Indonesia, muhammadhanif@upi.edu

\section{Budi Setiawan}

Universitas Pendidikan Indonesia, Indonesia, budi_setiawan@upi.edu

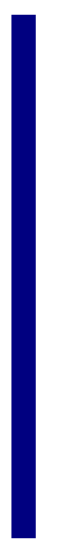

The aim of this study is to find out the factors on counsellor's effective skills towards the effects obtained through students' career guidance. Data from Secondary High School Department (DIKMEN) were analysed to investigate the mediation effect of counsellors' counselling skills to career guidance by applying SPSS 18.0. There was continual increase of self-efficacy regarding to students' satisfaction with the skilled career guidance counsellors. This study investigated the long-term stability of the positive effects obtained quantitatively done by the counsellors with improved effective counselling skills on students' career guidance. The result of the study showed that there are seven factors which become the key factors to effective counseling skill to improve the effective counseling skill and the effectiveness of individual counseling namely; attending, leading, reflecting, summarizing, interpreting, confronting, and informing/ advising. By acquiring those seven skills, the counselors contributed significantly to improve the effectiveness of individual counseling towards career guidance.

Keywords: career guidance, career development, counsellor, counselling skill, major satisfaction

\section{INTRODUCTION}

A school counselor as one of the education personnel is demanded professionally to able to run his or her profession well, that is able to give the service of an expert in guidance and counseling. A set of competencies is necessary to master in order to be able to give counseling assistance professionally. The competence which has to be possessed by a counselor related to counseling is a holistic counseling skill. The competence of counseling skill is basic competence in line with the present demand and development since the success of the work of a school counselor is determined in part by how he or she implements counseling skill in the individual counseling. The comprehension of the

Citation: Asrowi., Hanif, M., \& Setiawan, B. (2021). Career Development: The Role of Career Counsellor towards Job Counselling. International Journal of Instruction, 14(1), 661-672. https://doi.org/10.29333/iji.2021.14140a 
theories and practices is required in the implementation of counseling skill so that individual counseling can run effectively. The theoretical and practical comprehensions will strengthen the professional competence of a counselor.

The prove that the increase policy interest in career guidance provision is the evidence of overlapping policy reviews done by influential international organizations (Watts, 2012) in the last decade. According to the Organisation for Economic Cooperation and Development's definition, the services with the goal of helping people of any age and at any point throughout their lives to manage their careers is called as career guidance (OECD, 2004). Schools must acknowledge their responsibility towards guiding young people in a lifelong job and career development to meet the changing demands of society internationally (Perdrix, Stauffer, Masdonati, Massoudi, \& Rossier, 2011).

The concept of career development is to support individuals to be the subjects of their own being. At one time, career guidance took the form of the directive method where a professional guided young people who were graduating school and beginning to go into the job market relatively (Savickas, 2003). In today's context, three components of career guidance services can be categorized (Watts, 2010): 1) Career information: This is provided in various formats and is concerned with information on the labour market, career paths, jobs, and courses; 2) Career education: This is part of the curriculum and focusses on helping young people to develop their abilities for managing their job and career; 3) Career counseling: This is conducted on an individual basis, focussing on the career issues faced by young people.

Career guidance has been connected to self- efficacy, and people with high self-efficacy have bigger outcome expectations than people with low one (Day \& Allen, 2004). Research has also shown that low levels of self-efficacy in career development will lead to an avoidance of career decision-making behavior and less job satisfaction. Furthermore, high levels of self-efficacy in career development are related to the success of career planning and decisiveness (Swanson, 1995; Whiteley, 1984).

People with greater effort may have more positive outcome expectations, consequently, achieving successful career development. In vocational high school, students are at a very crucial stage because they are supposed to set their career development such as career planning (Winters, Meijers, Kuijpers, \& Baert, 2009).

Major satisfaction also may also be a proxy for later job satisfaction and career success because many college programs cannot be run without their respective social and vocational environments (Astin, 1965). Furthermore, studies investigating major satisfaction are limited in a job and career development literature and the findings have been inconclusive (Savickas, 2003; Watts, 2012). For students, major satisfaction is equal to job satisfaction because, like work environments, academic environments vary with respect to the opportunity to use various skills and interests (Allen, 1996).

According to Urie Bronfenbenner, counselors are in strategic positions. In this circle, such type of jobs choosen, interactions, in which the individual is involved and those between significant other, can affect and be affected by individual. Counselors are to be head to head to individuals or students who also embed lifelong learning principles. The 
open opportunity can lead students to build understandings about career options, actualize self potentials, gain knowledge on jobs choosen together, and learn to live with the society in the working area.

With this necessity, this study aimed to investigate the key factors influencing the counselors to provide effective counseling towards students' career guidance. This study focused on the long term effects of counseling skills, career guidance and students' major satisfaction.

\section{METHOD}

This research uses descriptive quantitative approach by distributing the questionairre and conducting interview, observation, interview, and inventory. A descriptive statistic (means and standard deviation) and a one-way analysis of variance (ANOVA) was applied to analyze the data. The interview is done person to person in 20 minutes for 32 participants. The interview result was transcribed and used to support the findings gained from the questionnaire, observation and inventory.

The subject of this research was the Guidance and Counseling teachers with bachelor degree and non-Guidance and Counseling education background but they are on duty as the Guidance and Counseling teachers at the junior high schools in Solo city. This research used the experiment method with one group of pretest and postest design.

This study used the Secondary High School Department (DIKMEN) data produced by the Vocational High Shcool Section of Ministry Education and Culture 2017 to 2018. The data contains various educational and vocational variables related to students, parents, teachers and school administers. DIKMEN has been gathering data on cohorts of students of middle schools, high schools and vocational and technical schools since 2004. This study used the data collected on vocational high school students because the data concerned students progressing from middle school to college. This made it possible to figure out the long-term effect of various factors on college life including career guidance, which the students had encountered two years previously.

The final number of observations in the data of this study were 32 . Male teachers comprised $70.3 \%$ of the sample, while female teachers comprised $29.7 \%$ of the sample.

\section{FINDINGS AND DISCUSSION}

The result of the preliminary study indicates that 11 out of 32 Guidance and counseling teachers $(34.38 \%)$ have medium level of comprehension on the basic theory of counseling skill and 21 teachers have $(65.63 \%)$ have low level of comprehension on the basic theory of counseling skill. Therefore, the average score in the comprehension on the theory which was achieved in majority is in the category of low level (1)

Then, the profiles of the counseling practice in the preliminary study on 20 Guidance and Counseling teachers of the junior secondary schools in Solo city are as follows: (15) teachers $(75 \%)$ achieve medium score while 5 teachers acieve low score in the skill to pay attention to the counselees while 5 teachers (25\%) achieve low score; (2) 10 teachers $(50 \%)$ achieve medium score while 10 teachers $(50 \%)$ achieve low score in the 
skill to lead conversation; (3) 2 teachers (10\%) achieve medium score while 18 teachers $(90 \%)$ achieve low score in the reflection skill; (4) 12 teachers $(60 \%)$ achieve low score in the concluding skill while 8 teachers (40\%) achieve very low score; (5) 12 teachers $(60 \%)$ achieve medium score in the confronting skill while 8 teachers $(40 \%)$ achieve low score; (6) 12 teachers $(60 \%)$ achieve medium score in the intepreting skill while 8 teachers (40\%) achieve low score; and (7) 11 teachers (55\%) achieve medium score in the skill and advice while 9 teachers (45\%) achieve low score. Therefore, the average score in the counseling skill practice is in the categories of medium, low and very low level.

It is empirically necessary to admit and realize the fact that the Guidance and Counselling teachers on field still highly vary in their competence and education background. Even though they are equally the scholars in Guidance and Counselling field, they have different perceptions and quality levels. The difference in their scholarly background, moreover, causes a great difference since they have never acquired the scientific fundamentals of Guidance and Counselling. It is such differences that cause difference in giving counselling and have negative impact toward the effectiveness of the individual counselling. The scope of this research is the Guidance and Counselling who do not have Guidance and Counselling background or the non- Guidance and Counselling teachers who are given the intervention of counselling skill so that their effectiveness counselling improves.

The development of counselling skill which becomes the focus of this research starts from the theories of counselling skill (Brammer, 1985; Carkhuff, 1969; Barbara Okun, 1982; McCubbin \& Dahl, 1985; Ivey, 1987; Cormier and Cormier, 1991; and Gail King, 2001) which emphasize the importance of counselling skill to be built in a school counsellor. Furthermore, Brammer (1985: 62), in relation to the focus, affirms that counselling skill is a series of knowledge and skill which has to be learnt and put into practice continuously in order to generate a counsellor who can help give assistance or counselling service to the counselee. Viewing from the psychology of learning, Gagne (1984: 11) affirms that if an individual continuously learns in a certain range as a result of the learning experience. Particularly, his or her behaviour will change as a result of the learning experience. Likewise, a Guidance and Counselling teacher will be able to give counselling knowledge and skill professionally.

Based on the results of the previous and preliminary studies, which were theoretical and empirical ones, this research is specialized to develop counselling skill in order to improve the effectiveness of the individual counselling given by the Guidance and Counselling teachers.

The results of the research and testing on the hypothesis are as follows:

Hypothesis Testing 1: The Profile of the initial Skill of Individual Counseling of the Guidance and Counseling teachers.

The mastery on the theories is the foundation on the practice of counseling skill. The profiles of the mastery of 32 Guidance and Counseling teachers on counseling skill at the preliminary study indicate that 11 out of them or $34.38 \%$ have medium level of 
comprehension on counseling theories and 21 out of them or $65.63 \%$ have low level of omprehension on counseling theories.

Then, the profile of the counseling practice at the preliminary study on 20 Guidance and Counseling teachers related to the practice of counseling skill at the junior high school in the territory of Solo city indicates the results as follows: (1) 15 out of them or $75 \%$ achieve medium score for skill to pay attention and 5 out of them or $25 \%$ achieve low score for skill to pay attention; (2) 10 out of them or $50 \%$ achieve low score for skill to lead conversation; (3) 2 out of the 20 teachers or 10 percent achieve medium score for skill to reflect client; (4) 12 out of them or $60 \%$ achieve low score for concluding skill and 8 out of them or $40 \%$ achieve very low score for concluding skill; (5) 12 out of them or $60 \%$ achieve low score for confronting skill and 8 out of them or $40 \%$ achieve low score for confronting skill; (6) 12 out of them or $60 \%$ percent achieve medium score for intepreting skill and 8 out of them or $40 \%$ achieve low score for intepreting skill; (7) 11 out of them or $55 \%$ achieve medium score for skill to give Skill and advice and 9 out of them or $45 \%$ achieve low score for skill to give skill and advice. Therefore, the average score for the practice of counseling skill achieved lies in the categories of medium, low, and very low scores. Following the intervention, the average scores rises to $47.62 \%$.

Hypothesis Testing 2: The Development of Effective Counseling Skill to Raise the Effectiveness of Verbal Language in Verbal Aspect Individual Counseling. Fact shows that the Improve in the average score of verbal aspect counseling skill is believed to be the caused by the treatment given by the researcher based on the data and the analysis. The specific description of each skill on pretest and postest can be seen on table below:

Table 1

The result of pair test on seven counselling skills

\begin{tabular}{llllllllll}
\hline No & Aspect & Pretest & \multicolumn{3}{c}{ Postest } & Variant & $\begin{array}{l}\text { Varian } \\
\text { Postest }\end{array}$ & $\begin{array}{l}\text { Sig } \\
\text { (2 tailed) }\end{array}$ & Note \\
\cline { 3 - 6 } & & Mean & Std. D & Mean & Std. D & Pretest & Pon \\
\hline 1. & Aspect 1 & 6.312 & 1.049 & 9.353 & 0.392 & 1.100 & 0.154 & 0.000 & Sig \\
\hline 2. & Aspect 2 & 6.498 & 1.525 & 9.290 & 0.428 & 2.326 & 0.184 & 0.000 & Sig \\
\hline 3. & Aspect 3 & 5.183 & 0.795 & 7.658 & 0.282 & 0.633 & 0.080 & 0.000 & Sig \\
\hline 4 & Aspect 4 & 3.314 & 0.789 & 8.284 & 1.030 & 0.623 & 1.062 & 0.000 & Sig \\
\hline 5. & Aspect 5 & 2.971 & 0.603 & 8.253 & 0.479 & 0.364 & 0.230 & 0.000 & Sig \\
\hline 6. & Aspect 6 & 6.250 & 1.404 & 9.250 & 0.747 & 1.974 & 0.559 & 0.000 & Sig \\
\hline 7. & Aspect 7 & 6.400 & 0.882 & 9.000 & 1.038 & 0.779 & 1.079 & 0.000 & Sig \\
\hline
\end{tabular}

Table 1 is a description of pair test between pretest and postest of seven counselling skills. It shows that each of skill compared in before and after intervention resulting in a significant change. Based on the different mean test by using Wicoxon test, it is obtained a score of $\mathrm{p}<0.05$. it is clear that there is a strong evidence to reject 0 hypothesis. In other words, there is a significant difference of verbal counselling skill on each skill which is before and after intervention.

The total description of pretest-postest and total mean on the improvement of counselling skills towards the effectiveness of individual counseling are presented in table below; 
Table 2

The result of pair test on total prestet and postest

\begin{tabular}{lllllll}
\cline { 1 - 3 } Intervention & Mean & Std. Dev & Difference & t-test & Sig (2 tailed) & Note \\
\cline { 1 - 6 } Pretest & 39.926 & 5.783 & 24.160 & 12.992 & 0.000 & Sig \\
\cline { 1 - 3 } Postest & 61.086 & 2.211 & & & & \\
\hline
\end{tabular}

Based on the dta mentioned on the pretest assessment showed the mean score : 36.926 , postest mean score : 61.08. with the mean difference of 24.16. This shows that each counseling skill gave significant difference of improvement between before and after trestment. The improving of mean score above can be seen on the graph 1 below;

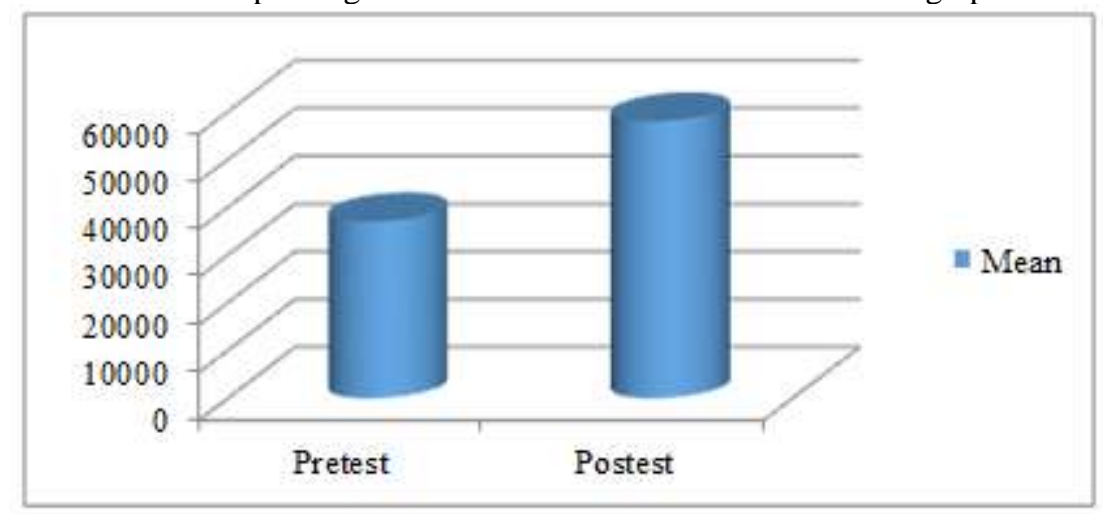

Figure 1

The improvement of mean pretest and postest verbal counseling skill

Based on the graph above, it can be concluded that the data and analysis applied can be affirmed to be able to improve the mean score of counseling skill on verbal aspects towards its effectiveness caused by the intervention given by the researcher.

Hypothesis Testing 3: The Development of Effective Counseling Skill to Raise the Effectiveness of the Individual Non-verbal Aspects of Counseling Skill.

The result indicate that there is a significant change in each of the non- verbal aspect counseling skills from the pre-intervention stage to the post-interventon stage. In other words, there is a significant difference in each of the non verbal counseling skills between that of the pre- intervention stage and that of the post-intervention stage. The specific description of each counseling skill on non- verbal aspect of pretest and postest is given on table below; 
Table 3

The description of pair test on pretest- postest and result of different mean test on the development of counseling skill to improve the effectiveness of individual counseling on non-verbal language

\begin{tabular}{llllllllll}
\hline \multirow{2}{*}{ No } & Aspect & Pretest & \multicolumn{3}{c}{ Postest } & Variant & $\begin{array}{l}\text { Varian } \\
\text { Postest }\end{array}$ & $\begin{array}{l}\text { Sig } \\
\text { (2 tailed) }\end{array}$ & Note \\
\cline { 3 - 8 } & & Mean & Std. D & Mean & Std. D & Pretest & \\
\hline 1. & Aspect 1 & 5.339 & 1.575 & 8.733 & 0.773 & 2.481 & 0.598 & 0.000 & Sig \\
\hline 2. & Aspect 2 & 5.106 & 1.488 & 8.758 & 0.428 & 2.216 & 0.183 & 0.000 & Sig \\
\hline 3. & Aspect 3 & 5.481 & 1.100 & 8.857 & 0.413 & 1.212 & 0.171 & 0.000 & Sig \\
\hline 4 & Aspect 4 & 4.154 & 0.413 & 6.792 & 0.364 & 1.158 & 0.133 & 0.000 & Sig \\
\hline 5. & Aspect 5 & 4.580 & 0.843 & 8.735 & 0.384 & 0.712 & 0.148 & 0.000 & Sig \\
\hline 6. & Aspect 6 & 5.541 & 1.098 & 8.979 & 0.530 & 1.207 & 0.282 & 0.000 & Sig \\
\hline 7. & Aspect 7 & 6.000 & 1.513 & 8.375 & 0.582 & 2.289 & 0.339 & 0.000 & Sig \\
\hline
\end{tabular}

The description of total pretest- postest and its mean to the improvement of non verbal counseling skill towards the effectiveness of individual counseling skill is presented below;

Table 4

The result of pair test on individual counseling skill data on non- verbal aspect before and after

\begin{tabular}{lllllll}
\hline Intervention & Mean & Std. Dev & Difference & t-test & Sig (2 tailed) & Note \\
\cline { 1 - 5 } Pretest & 35.562 & 6.975 & 22.656 & 11.622 & 0.000 & Sig \\
\cline { 1 - 3 } Postest & 59.218 & 2.058 & & & & \\
\hline
\end{tabular}

It can be concluded that each of the couseling skills indicates a sufficiently convincing correlation and contribution of each counseling skills shows a highly significant result. It can be concluded that the correlation and the contribution of each of the counseling skills shows a highly significant result. It can be concluded that the correlation and the contribution of verbal aspect counseling skills are caused by the tretment given by the researcher. The data showed the seven skills of non verbal conseling improve from mean score 36.56 before treatmen to 59.21 after treatment. Table 4 is an illustration of scores in pairs of those of the pre-intervention stage and those of the post -intervention stage of seven non-verbal aspect counseling skills indicates that the pre-intervention mean is as much as 36.562 and then it goes up to 59.218 in the post-intervention stage. Figure 2 below illustrates the improvement in the average score above.

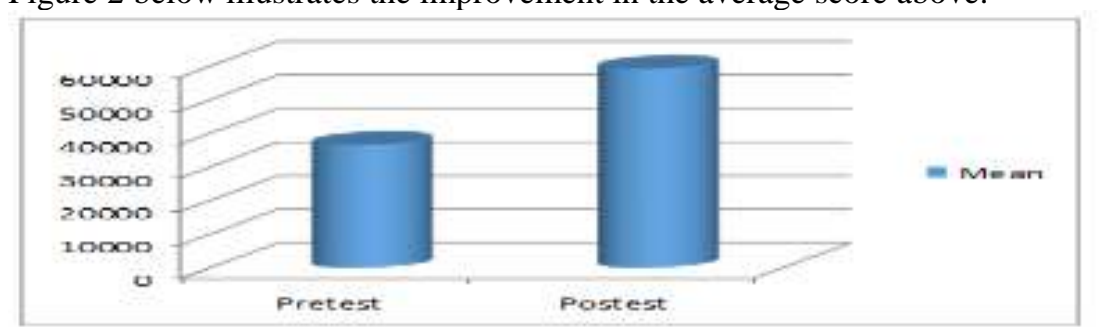

Figure 2

The improvement of pretest-postest mean score on non verbal counseling skill 
The improve in the average scores of the effectiveness of non verbal aspect counseling skills is believed to be caused by the treatment given by the researcher.

Hypothesis 4: shows verbal counseling skill gave contribution to effectiveness of individual counseling; skill 1 (48.9), skill 2 (53.70), skill 3 (20.92), skill 4 (20.90), skill 5 (31.85), skill 6 (24.70) and skill 7 (79.39). It means that the counseling skills given by the researcher contributed significant skills to the effectiveness of individual counseling. The specific description of each counseling skill on non- verbal aspect of pretest and postest is given on table below;

Table 5

The description of kolmogorov- smirnov pair test data and correlational test (contribution) on verbal language

\begin{tabular}{llllllllll}
\hline No & Aspect & Pretest & & Postest & & $\begin{array}{l}\text { Pearson } \\
\text { Corr }\end{array}$ & $\begin{array}{l}\text { Contrib } \\
\text { ution \% }\end{array}$ & $\begin{array}{l}\text { Sig } \\
(2 \text { tailed })\end{array}$ & Note \\
\cline { 3 - 10 } & & Mean & Std. D & Mean & Std. D & & & & \\
\hline 1. & Aspect 1 & 0.16 & 0.141 & 0.318 & 0.000 & 0.699 & 48.90 & 0.001 & Sig \\
\hline 2. & Aspect 2 & 0.165 & 0.159 & 0.351 & 0.000 & 0.733 & 53.70 & 0.000 & Sig \\
\hline 3. & Aspect 3 & 0.198 & 0.040 & 0.237 & 0.000 & 0.457 & 20.92 & 0.043 & Sig \\
\hline 4 & Aspect 4 & 0.249 & 0.002 & 0.341 & 0.000 & 0.457 & 20.90 & 0.043 & Sig \\
\hline 5. & Aspect 5 & 0.204 & 0.029 & 0.301 & 0.000 & 0.564 & 31.85 & 0.010 & Sig \\
\hline 6. & Aspect 6 & 0.313 & 0.000 & 0.298 & 0.000 & 0.497 & 24.70 & 0.026 & Sig \\
\hline 7. & Aspect 7 & 0.194 & 0.048 & 0.315 & 0.000 & 0.108 & 79.39 & 0.652 & Sig \\
\hline
\end{tabular}

Language skill took a very important role in revealing the client's problems and it also functioned as a therapy.language expressed in friendly, polite, and respective to the client's response relieved his or her emotion. The table above also describes that each of the counseling skill on verbal aspect starting from the one to seven give significant contribution to the effectiveness of individual counseling. It is clearly seen on the table that the result of statistic analysis on pre-postest has significant correlation and contribution. Figure 3 shows the contribution on each skills to the effectiveness on individual counselling below.

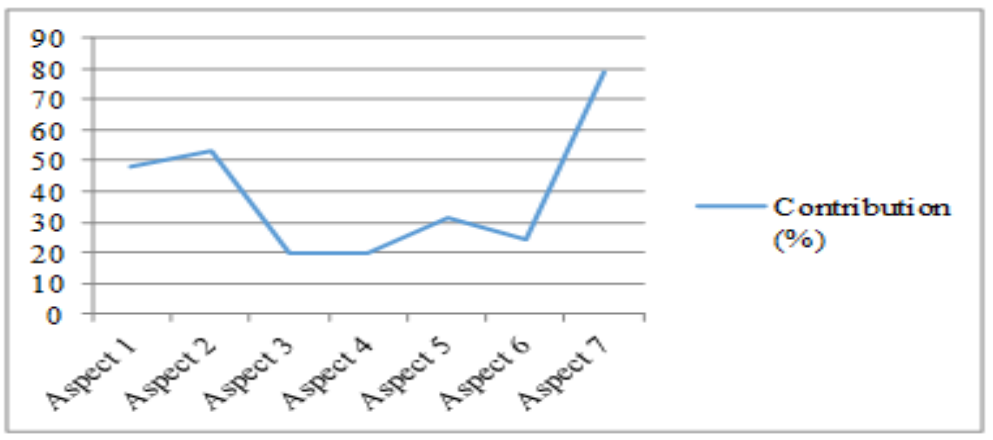

Figure 3

The contribution of counseling skill on verbal aspect to the effectiveness of individual counseling 
Based on the graph above, it can be concluded that every counseling skill shows a significant correlation and its contribution to every counseling skill as well.

Hypothesis 5 Non-verbal skill (gesture and body language): This skill contributed to the effectiveness of individual counseling as described in the following data; skill 1 (50.10), skill 2 (40.30), skill 3(16.20), skill 4 (17.78). skill 5 (42.20), skill 6 (15.70), skill 7 (35.00). The specific description of each counseling skill on non- verbal aspect of pretest and postest is given on table below;

Table 6

The description of kolmogorov- smirnov pair test data and correlational test (contribution) on non-verbal language

\begin{tabular}{|c|c|c|c|c|c|c|c|c|c|}
\hline \multirow[t]{2}{*}{ No } & \multirow[t]{2}{*}{ Aspect } & \multicolumn{2}{|l|}{ Pretest } & \multicolumn{2}{|l|}{ Postest } & \multirow{2}{*}{$\begin{array}{l}\text { Pearson } \\
\text { Corr }\end{array}$} & \multirow{2}{*}{$\begin{array}{l}\text { Contribution } \\
\%\end{array}$} & \multirow{2}{*}{$\begin{array}{l}\text { Sig } \\
\text { (2 tailed) }\end{array}$} & \multirow[t]{2}{*}{ Note } \\
\hline & & Mean & Std. D & & & & & & \\
\hline 1. & Aspect 1 & 0.1555 & 0.200 & 0.201 & 0.034 & 0.708 & 50.10 & 0.000 & Sig \\
\hline 2. & Aspect 2 & 0.158 & 0.200 & 0.163 & 0.169 & 0.635 & 40.30 & 0.003 & Sig \\
\hline 3. & Aspect 3 & 0.132 & 0.200 & 0.170 & 0.134 & 0.402 & 16.20 & 0.079 & Sig \\
\hline 4 & Aspect 4 & 0.169 & 0.137 & 0.281 & 0.000 & 0.422 & 17.78 & 0.064 & Sig \\
\hline 5. & Aspect 5 & 0.106 & 0.200 & 0.165 & 0.157 & 0.649 & 42.10 & 0.002 & Sig \\
\hline 6. & Aspect 6 & 0.189 & 0.060 & 0.240 & 0.004 & 0.396 & 15.70 & 0.084 & Sig \\
\hline 7. & Aspect 7 & 0.150 & 0.200 & 0.190 & 0.056 & 0.592 & 35.00 & 0.006 & Sig \\
\hline
\end{tabular}

The table above describes that every counseling skill on non-verbal aspect give a very significant contribution to the effectiveness of individual counseling. The graph below also states the contribution on each skill to the effectiveness of individual counseling.

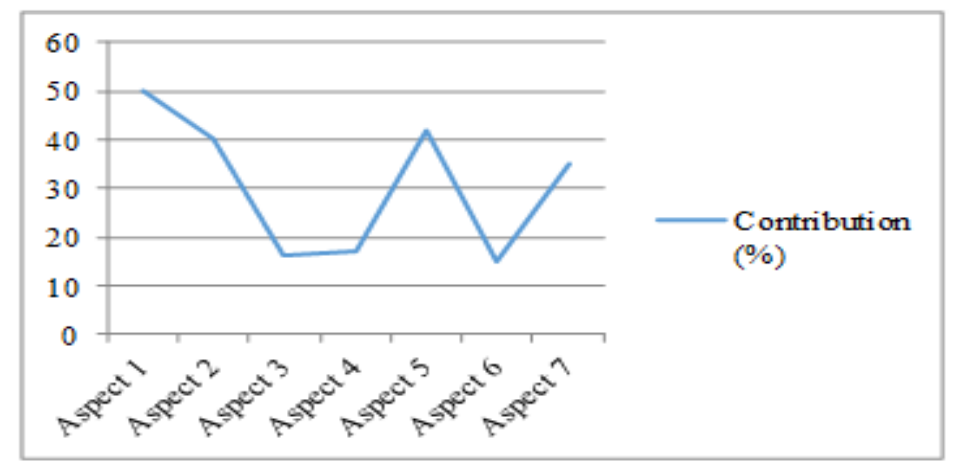

Figure 4

The contribution of counseling skill to the effectiveness of individual counseling

It can be drawn a counclusion that the seven non-verbal skills gave significant contribution to the effectiveness of individual counseling. The reason is that gesture and body language together with verbal language help the client to explore his or her problems, counseling in terms of verbal and non- verbal.

Hypothesis 6: Counseling skills are effective to improve the effectiveness of individual counseling of the Guidance and Counseling teachers of junior high schools. It ctn be concluded that the development of counseling skills is effective to improve the 
effectiveness of individual counseling. The specific description of each counseling skill on non- verbal aspect of pretest and postest is given on table below;

Table 7

The description of pair data on pretest postest verbal language and pretest postest nonverbal

\begin{tabular}{lccccccc}
\hline Skill & N & Minimum & Maximum & Mean & St. D & $\begin{array}{l}\text { Sig } \\
(2 \text { tailed })\end{array}$ & Note \\
\hline Pre Verbal & 20 & 29.580 & 44.961 & 36.926 & 5.783 & 0.000 & Sig \\
\hline Post Verbal & 20 & 56.751 & 65.835 & 61.086 & 2.211 & 0.000 & Sig \\
\hline Pre Non Verbal & 20 & 22.140 & 44.023 & 36.562 & 6.975 & 0.000 & Sig \\
\hline Post Non Verbal & 20 & 54.810 & 63.024 & 59.218 & 2.058 & 0.000 & Sig \\
\hline
\end{tabular}

Based on the result of non parametric test used to test the different score of counseling skill to the effectiveness of counseling skill both on verbal and non verbal aspect between pre-postest intervention apply the Wilcoxon test. The statistical analysis comes to significant when $p=0.000$ less than $p<0,05$, then it can be said that the development of counseling skill is effective to improve the individual counseling of Guidance and Counseling Teachers.

Then, the graph 5 below describes the average improvement of pre-postest non-verbal aspect.

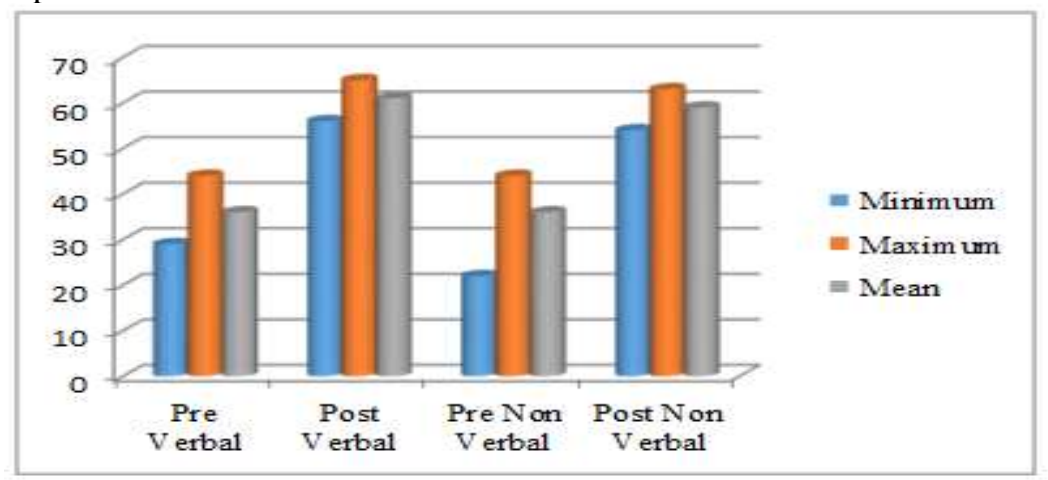

Figure 5

The average improvement of pre-postest non-verbal aspect.

The effectiveness of individual skill is shown in the following data; Total pretest score on verbal skill shows minimum: 29.58, max: 44.96, mean: 36.92 and postest verbal: 56.75, max: 65.83, mean: 61.08, pretest on non-verbal: minimum: 22.14 , max: 44.02, postest on non-verbal minimum: 54.81, max: 63.02 and $\min : 59.21$. hence, the development of counseling of 7 skills was effective to the individual counseling. The result of this research was not only in the term of quantitative but also from qualitative score. The fact indicates that students felt psychologically safe in learning through this approach as compared to the previous treatment.

According to the counseling is considered effective when it is conducted holistically in 7 ways above. The counselor is demanded to be able to demonstrate attending skills, 
listening skills, reflecting skills, paraphrasing skill, summarizing skill, confronting skill, advising skill, emphaty skill by using communicative, warm, and responsive verbal and non verbal language.

\section{CONCLUSION}

There are seven factors which become the key factors to effective counseling skill to improve the effective counseling skill and the effectiveness of individual counseling in this research. Such factors are: (1) accumulation of the use of seven counseling skills in one integral and holistic series; (2) tenderness and personality of the counselor in accepting the counselee as a person in huge need; (3) behavior of the counselor in this research is built through the attitudes of acceptance, unconditional positive regard, repect, understanding, reassurance, emphaty,, and warmth, all of which are covered in the material of seven counseling skills; (4) creating the counseling climate contains therapeutic elements and it is useful to reduce emotional, behavioral and cognitive stress of the counselee; (5) counseling skills can help the counselee to able to change his/ her behavior through learning helping relationship which enable him/ her to find the self meaning and the right and proper position; (6) the counselee believes that the behavior of the counselee is composed of cognitive, emotional, and motoric responses . the counselor can stimulate the counselee through those counseling skills to change him/herself into the counseling process and henceforth; (7) seven counseling skills (attending, leading, reflecting, summarizing, interpreting, confronting, and informing/ advising can build the self concept of the counselor him/ herself as well as become therapy. The counselors prove that the counseling skills that they have put into practice all this time are effective to improve the effectiveness of individual counseling. The counselees also directly go through and feel the result of counseling by themselves.

\section{REFERENCES}

Allen, M. L. (1996). Dimensions of educational satisfaction and academic achievement among music therapy majors. Journal of Music Therapy, 33, 147-160

Brammer, L.M. (1979). The Helping Relationship: Process and Skills. Englewood Cliff, New Jersey: Prentice Hall, Inc.

Corey, G. (2005). Theory and Practice of Counseling \& Psychotheraphy. United State of America: Thomson, Brooks/ Cole.

Day, R., \& Allen, T. D. (2004). The relationship between career motivation and selfefficacy with career success. Journal of Vocational Behavior, 64, 72-91.

Gagne \& Briggs. (1979). Principal of Instructuion Design. New York: Holt, Rinnehart and Winston.

King, G. (1999). Counseling Skill For Teachers Talking Matters. United State of America: Open University Buckingham-Philadelphia

OECD (2004). Career guidance and public policy: Bridging the gap. OECD, Paris. 
Perdrix, S., Stauffer, S., Masdonati, J., Massoudi, K., \& Rossier, J. (2011). Effectiveness of career counseling: A one-year follow-up. Journal of Vocational Behavior, 80, 565-578.

Savickas, M. (2003). The next decade in vocational psychology: Mission and objectives. Journal of Vocational Behavior, 59, 284-290.

Swanson, J. L. (1995). The process and outcome of career counseling. In W. B. Walsh \& S. H. Osipow (Eds.), The handbook of vocational psychology (pp. 217-259). Mahwah, NH: Lawrence Erlbaum.

Watts, A. G. (2010). Career guidance and post- secondary vocational education and training. A paper prepared for the OECD review of post- secondary vocational education and training, skills beyond school.

Watts, A. G. (2012). Current issues and future directions on career education. A paper prepared for the Career Education International Forum. Seoul, Korea.

Whiteley, J. M. (1984). A historical perspective on the development of counseling psychology as a profession. In S. D. Brown \& R. L. Lent (Eds.), Handbook of Counseling Psychology (pp. 3-55). New York: John Wiley.

Willis, S. S. (2007). Konseling Individual Teori dan Praktek. Bandung: Alfabeta.

Winters, A., Meijers, F., Kuijpers, M., \& Baert, H. (2009). What are vocational training conversations about? Analysis of vocational training conversations in Dutch vocational education from a career learning perspective. Journal of Vocational Education and Training, 61, 247-266.

Yusuf, M. (1995). Program Pengembangan Profesionalitas Petugas Bimbingan Sekolah. Program Pascasarjana IKIP Bandung. 